\title{
APLIKASI ERGONOMI UNTUK MENINGKATKAN KINERJA OPERATOR DAN OUTPUT PRODUKSI PADA PROSES TAPER
}

\author{
Maulidina Achmad \\ PT. Indospring Tbk \\ Email : teknik.industriunmuh@gmail.com
}

ABSTRAK

D T. Indospring Tbk adalah sebuah perusahaan otomotif manufacturing yang memproduksi spring dengan mutu tinggi dengan menerapkan mutu ISO 9002:2000. Hasil produksinya selama ini untuk memenuhi pemesanan dari dunia otomotif dalam negeri maupun luar negeri. Rata-rata output produsi (PO) Hot Coil perbulan $=40.000 \mathrm{pcs} / \mathrm{bln}$, kendala yang membuat output kurang maksimal adalah output taper tidak sesuai dengan standart (tebal dan panjang), dan adanya keluhan pada bagian tubuh seperti bahu kiri, bahu kanan, pinggang, lengan bawah kiri dan lengan bawah kanan.Skripsi ini bertujuan untuk mengetahui keluhan fisik operator sehingga penulis dapat membuat alternatif solusi yang baik guna mengurangi keluhan fisik yang terjadi selama proses taper dan membuat rancangan yang ergonomis dengan perhitungan data anthropometri dan data persentil.

Kata kunci: ergonomi, keluhan fisik, nordic body map, biomekanika

\section{PENDAHULUAN}

\section{Latar Belakang}

Dalam sebuah pelaksanaan kegiatan produksi pada perusahaan di perlukan kenyamanan, kesehatan, keselamatan, dan keamanan kerja. agar pelaksanaan kerja dapat lancar, aman, dan nyaman maka dalam perencanaan ruang, perencanaan perabot perlu mempertimbangkan faktor ergonomic. Postur kerja yang salah sering diakibatkan oleh letak fasilitas yang kurang sesuai dengan anthopometri operator, sehingga mempengaruhi kinerja operator.

PT. Indospring Tbk adalah sebuah perusahaan otomotif manufacturing.Setiap hari permintaan pelanggan di dunia otomotif terus bertambah, maka perusahaan perlu menambah kapasitas produksin- ya, Proses taper merupakan awal proses dari pembuatan spring, dengan cara memipihkan salah satu sisi ujung material yang nantinya akan diproses menjadi spring. Taper berfungsi sebagai landasan coil spring agar dapat berdiri dengan sempurna. Bertambahnya jumlah pesanan konsumen membuat produksi hot coil harus menambah kapasitas produksinya untuk dapat memenuhi setiap pesanan konsumen. Dan rata-rata output produsi (PO) Hot Coil perbulan $=40.000 \mathrm{pcs} / \mathrm{bln}$.

Lingkungan yang sifatnya dinamis akan mempengaruhi kondisi kerja para operator. Oleh karena itu, untuk mengantisipasi hal tersebut maka pada proses taper wajib memperhatikan tentang kesehatan dan keselamatan kerja bagi setiap operator 
atau pekerjaannya dengan cara penyesuaian antara pekerja dengan metode kerja, proses kerja dan lingkungan kerja. Pendekatan ini dikenal dengan pendekatan ergonomi.

Tabel 1. Data PO Dengan Proses Taper

\begin{tabular}{|c|l|c|c|c|}
\hline \multirow{2}{*}{ NO } & \multirow{2}{*}{ PART NO } & 2013 & \multicolumn{2}{|c|}{2014} \\
\cline { 3 - 5 } & & Des'13 & Jan'14 & Feb'14 \\
\hline 1 & MB 109353 L (PHILIPINE) & 1080 & 840 & 1080 \\
2 & MB 109353 OE & 3960 & 6180 & 5040 \\
3 & MB 109353 RA & 750 & 300 & 300 \\
4 & MR 374478 & 120 & 480 & 720 \\
5 & MT 141233 & 500 & 300 & 300 \\
6 & MB 109924 & 550 & 300 & 300 \\
7 & TRUST AUTO & - & 50000 & - \\
\hline \multicolumn{2}{|c|}{ TOTAL } & 6960 & 13400 & 7740 \\
\hline \multicolumn{2}{|c|}{ RATA-RATA } & 6960 & \multicolumn{2}{|c|}{10570,0} \\
\hline
\end{tabular}

Tabel 2. Data Proses Taper

\begin{tabular}{|c|c|c|c|r|}
\hline \multirow{2}{*}{ Data Proses Taper } & 2013 & \multicolumn{2}{|c|}{2014} & \multirow{2}{*}{ Rata-rata } \\
\cline { 2 - 5 } & Des'13 & Jan'14 & Feb'14 & \\
\hline Rata-rata output Taper & 350 & 420 & 454 & 408 \\
\hline PO Bln & 6960 & 13400 & 7740 & 9367 \\
\hline Rata-rata PO Bin & 7000 & \multicolumn{2}{|c|}{10570} & 8785 \\
\hline Hari Dibutulukan & 20 & 25 & 23 & 23 \\
\hline
\end{tabular}

Dengan dasar rata-rata $\mathrm{PO} \mathrm{P} / \mathrm{N}$ dengan proses Taper 10.000 pcs, maka hanya $25 \%$ dari total PO produksi Hot Coil. Dari data yang tercantum diatas, maka untuk memastikan PO produksi terpenuhi adalah harus ditambahnya kapasitas produksi pada proses taper.tetapi identifikasi awal dari masalah yang terjadi pada tiap proses taper adalah efektifitas operator yang kurang produktif akibat 2 hal, yaitu :

1. Pada proses end heating belum terdapat visualsasi untuk menentukan panjang permukaan mate- rial yang akan di panaskan hal ini mengakibatkan operator hanya kira-kira dalam mengukur panjang permukaan material yang akan dipanaskan

2. Pada proses taper operator memindahkan material ke mesin A menuju mesin B dengan menggenggam material, beban dari material yang akan di taper sepenuhnya di topang oleh operator dalam frekuensi yang tidak sebentar mengakibatkan 20 operator berdasarkan kuisioner Nordic Body Map yang telah diberikan banyak mengalami keluhan rasa nyeri pada bagian bahu kiri , bahu kanan, pinggang, lengan bawah kiri, lengan bawah kanan

\section{Perumusan Masalah}

Berdasarkan latar belakang diatas maka dapat dirumuskan. Bagaimana mengaplikasikan ergonomi untuk meminimalkan keluhan fisik yang dialami oleh operator Taper produksi Hot Coil Spring sehingga output produksi dapat meningkat.

\section{Tujuaan Penelitian}

a. Mengetahui faktor - faktor yang mempengaruhi keluhan fisik.

b. Mengurangi keluhan fisik operator.

c. Merancang alat bantu yang ergonomis sehingga dapat mengurangi keluhan fisik

\section{Manfaat Penelitian}

a. Mendapatkan identifikasi penyebab kurangnya kinerja operator.

b. Memberikan rekomendasi perbaikan (improve- 
ment) untuk menanggulangi keluhan fisik yang dialami operator.

c. Memberikan alternatif solusi terbaik untuk menanggulangi kurangnya kinerja operator.

\section{TINJAUAN PUSTAKA}

\section{Ergonomi}

Ergonomi berasal dari kata yunani ergo yang berarti kerja dan nomos yang berarti hukum. Jadi ergonomi dapat diartikan sebagai ilmu yang mempelajari manusia dalam kaitannya dengan pekerjaan. Ergonomi dapat juga didefenisikan sebagai suatu ilmu yang memanfaatkan informasi mengenai sifat, kemampuan dan keterbatasan manusia untuk merancang system kerja. Dengan ergonomi, diharapkan manusia yang berperan sentral dalam suatu system kerja dapat bekerja lebih efektif dan optimal. Dengan demikian jelas bahwa pendekatan ergonomic akan mampu menimbulkan efektifitas fungsional dan kenyamanan pemakaian dari peralatan, fasilitas maupun lingkungan kerja yang dirancang(Wignjosoebroto, 1995).

Disiplin human engineering atau ergonomi banyak diaplikasikan dalam berbagai proses perancangan produk (man-made object) ataupun operasi kerja sehari-harinya. Sebagai contoh desain dari dials atau instrumental displays (man-machine interface) akan banyak mempertimbangkan aspek- aspek ergonomi ini. Demikian juga dalam sebuah stasiun kerja, semua fasilitas kerja seperti peralatan, material dan lain-lain haruslah diletakkan didepan dan berdekatan (jarak jangkauan normal) dengan posisi operator bekerja. Hal ini sesuai dengan prinsip-prinsip ekonomi gerakan. Dengan mengaplikasikan aspek-aspek ergonomi atau human engineering, maka dapat dirancang sebuah stasiun kerja yang bisa dioperasikan oleh rata-rata manusia. Disiplin ergonomi khususnya yang berkaitan dengan pengukuran dimensi tubuh manusia (anthropometri) telah menganalisa, mengevaluasi dan membakukan jarak jangkauan yang memungkinkan rata manusia untuk melaksanakan kegiatanya dengan mudah dan gerakan-gerakan yang sederhana. Contoh lain dari aplikasi disiplin ergonomi juga bisa dilihat dalam proses perancangan peralatan kerja (tools) untuk penggunaan yang lebih efektif. Dengan demikian manusia tidak lagi harus menyesuaikan dirinya dengan mesin yang dioperasikan (the man fits to the design), melainkan sebaliknya yaitu mesin yang diancang dengan terlebih dahulu memperhatikan kelebihan dan keterbatasan manusia yang mengoperasikannya (Wignjosoebroto, 1995).

\section{Sikap Kerja Ergonomi}

Posisi tubuh dalam bekerja ditentukan oleh jenis pekerjaan yang dilakukan. Masing-masing posisi kerja mempunyai pengaruh yang berbeda- 
beda terhadap tubuh. Menurut Tarwaka dan Bakri (2004), batasan stasiun kerja untuk posisi duduk dan berdiri, sebagai berikut :

1. Pekerjaan dilakukan dengan duduk dan pada saat lainya dilakukan dengan berdiri saling bergantian.

2. Perlu menjangkau lebih dari $40 \mathrm{~cm}$ ke depan dan atau $15 \mathrm{~cm}$ diatas landasan.

3. Tinggi landasan kerja 90-120 cm.

Sikap tubuh dalam beraktivitas pekerjaan diakibatkan oleh hubungan antara dimensi kerja dengan variasi tempat kerja. Sikap tubuh (posture) manusia secara mendasar keadaan istirahat menurut Pheasant (1991), yaitu :

\section{Sikap berdiri (standing).}

Sikap berdiri adalah posisi tulang belakan vertical dan berat badan bertumpu secara seimbang pada dua kaki.

2. Sikap duduk (sitting)

Sikap dimana kaki tidak terbebani dengan berat tubuh dan posisi stabil saat bekerja.

3. Sikap berbaring (lying).

Sikap terlentang dimana bagian lordosis dipertahankan dengan paha dan lutut $45^{\circ}$.

4. Sikap jongkok (squatting)

Sikap kerja dimana posisi lutut fleksi max, paha, badan fleksi max, dan lumbal juga fleksi max.

Menurut Barnes (1980), untuk menghindari postur kerja yang demikian dilakukan pertimbangan ergonomi, yaitu :

1. Mengurangi keharusan bekerja dengan postur tubuh membungkuk dalam frekuensi kegiatan yang sering atau dalam jangka waktu yang lama.

2. Mengatasi hal ini, maka stasiun kerja dirancang dengan memperhatikan fasilitas kerja, seperti meja, kursi yang sesuai dengan anthropometri agar pekerja menjaga postur kerjanya tetap tegak dan normal. Ketentuan ini ditekankan bilamana pekerjaan dilakukan dengan posisi postur berdiri.

3. Pekerja tidak seharusnya menggunakan jarak jangkauan maksimum. Pengaturan postur kerja dalam hal ini dilakukan dalam jarak jangkauan normal (prinsip ekonomi gerakan).

4. Pekerja tidak seharusnya duduk atau berdiri pada saat bekerja dalam waktu yang cukup lama dengan posisi kepala, leher, dada, dan kaki berada dalam postur kerja miring.

5. Operator tidak seharusnya dipaksa bekerja dalam frekuensi atau periode waktu yang lama dengan tangan atau lengan berada dalam posisi diatas level siku yang normal.

\section{Anthropometri Dalam Ergonomi}

Istilah anthropometri berasal dari kata anthro yang berarti manusia dan metri yang berarti ukuran. Anthropometri secara luas akan digunakan sebagai 
pertimbangan - pertimbangan ergonomic dalam proses perancangan (design) produk maupun system kerja yang akan memerlukan interaksi manusia (Wignjosoebroto, 1995). Data anthropometri yang diperoleh akan diaplikasikan secara luas dalam hal:

1. Perancangan areal kerja (work station, interior mobil, dan lain-lain).

2. Perancangan peralatan kerja seperti mesin, equipment, perkakas (tools) dan sebagainya.

3. Perancangan produk konsumtif seperti pakaian, kursi/meja computer, dan lain-lain.

4. Perancangan lingkungan kerja fisik.

5. Data anthropometri akan menentukan bentuk, ukuran dan dimensi yang tepat berkaitan dengan produk yang dirancang dan manusia yang akan mengoperasikan / menggunakan produk tersebut. Dalam kaitan ini maka perancang produk harus mampu mengakomodasikan dimensi tubuh dari populasi terbesar yang akan menggunakan produk hasil rancangannya tersebut. Secara umum sekurang - kurangnya 90\% - 95\% dari populasi yang menjadi target dalam kelompok pemakai suatu produk haruslah mampu menggunakan dengan selayaknya. Pada dasarnya perataan kerja yang dibuat dengan mengambil referensi dimensi tubuh tertentu jarang sekali bisa mengakomodasikan seluruh range ukuran tubuh dari populasi yang akan memakainya. Jadi, sebelum menentukan data an- thropometri mana yang akan dipakai tentunya diketahui dulu sasaran konsumen yang akan memakai produk tersebut.

\section{Nordic Body Map (NBM)}

Salah satu alat ukur ergonomik sederhana yang dapat digunakan untuk mengenali sumber penyebab keluhan musculoskeletal adalah nordic body map. Nordic body map ini dipakai untuk mengetahui keluhan-keluhan yang dirasakan oleh para pekerja.

\section{Dimensi Anthropometri}

Data anthropometri dapat dimanfaatkan untuk menetapkan dimensi ukuran produk yang akan dirancang dan disesuaikan dengan dimensi tubuh manusia yang akan menggunakannya.

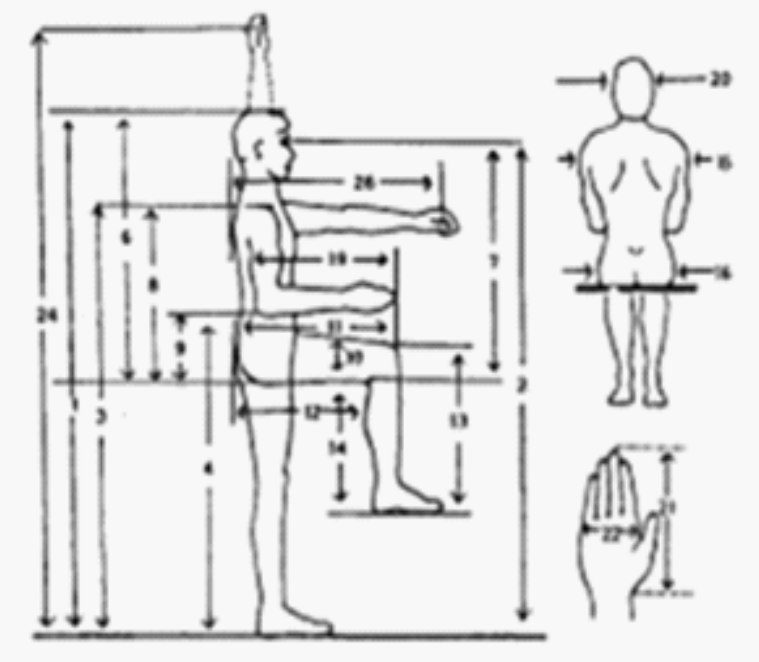

Gambar 1. Anthropometri Untuk Perancangan Produk Atau Fasilitas

\section{Distribusi Normal Dalam Anthropometri}

Penerapan data anthropometri, distribusi yang 
umum digunakan adalah distribusi normal (Nurmianto, 1996). Dalam statistic, distribusi normal dapat diformulasikan berdasarkan nilai rata-rata dan standart deviasi yang ada dapat ditentukan persentile sesuai table probabilitas distribusi normal.Persentil menunjukan jumlah bagian per seratus orang dari suatu populasi yang memiliki ukuran tubuh tertentu.

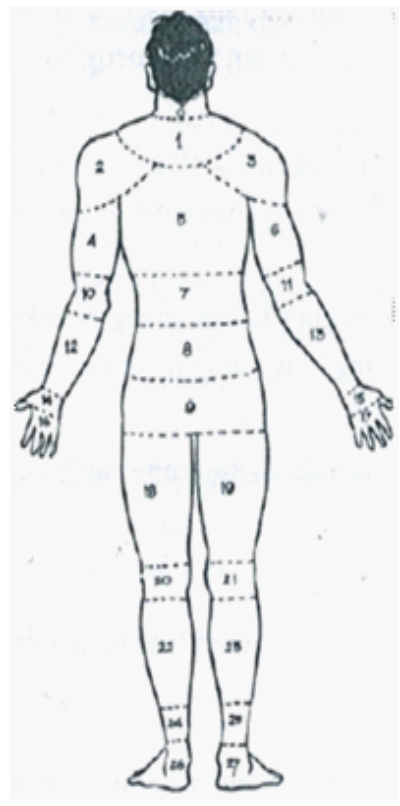

Gambar 2. Anthropometri

Ada dua hal penting yang harus selalu diingat bila menggunakan persentil. Pertama, suatu persentil anthropometri dari tiap individu hanya berlaku untuk satu data dimensi tubuh saja. Hal ini dapat dikatakan seseorang memiliki persentil yang sama ke-95 atau ke-90 atau ke-5, untuk keseluruhan dimensi tubuhnya. Hal ini hanya merupakan gambaran dari suatu makhluk dalam khayalan, karena seseorang dengan persentil ke-50 untuk data tinggi badanya, dapat saja memiliki persentil ke-40 untuk data tinggi lututnya, atau persentil ke-60 untuk data panjang lengannya seperti ilustrasi pada gambar

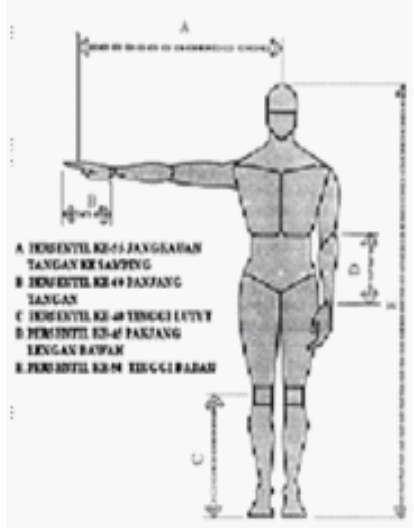

Gambar 3. Ilustrasi Persentil

Tabel 3. jenis persentil dan cara perhitungan dalam distribusi normal

\begin{tabular}{|c|l|}
\hline Persentil & \multicolumn{1}{|c|}{ Perhitungan } \\
\hline 1-St & $\bar{x}-2.325 \sigma_{x}$ \\
\hline 2.5-Th & $\bar{x}-1.96 \sigma_{x}$ \\
\hline 5-Th & $\bar{x}-1.645 \sigma_{x}$ \\
\hline 10-Th & $\bar{x}-1.28 \sigma_{x}$ \\
\hline 50-Th & $\bar{x}$ \\
\hline 90-Th & $\bar{x}+1.28 \sigma_{x}$ \\
\hline 95-Th & $\bar{x}+1.645 \sigma_{x}$ \\
\hline 97.5-Th & $\bar{x}+1.96 \sigma_{x}$ \\
\hline 99-Th & $\bar{x}+2.325 \sigma_{x}$ \\
\hline
\end{tabular}

Pengolahan Data Anthropemetri

Data mentah yang sudah didapatkan diuji terlebih dahulu dengan menggunakan metode statistic sederhana yaitu uji keseragaman, uji kecukupan (Wignjosoebroto, 1995). Hal tersebut dilakukan agar data yang diperoleh bersifat respresentatif, artinya data tersebut dapat mewakili populasi yang diharapkan.

a. Uji keseragaman data

Pengujian keseragaman data dilakukan untuk men- 
getahui :

1. Homogenitas data.

2. Apakah berasal dari satu populasi yang sama.

3. Data ekstrim atau yang berada di luar batas harus dihilangkan dan tidak perlu disertakan dalam perhitungan.

Rumus yang digunakan dalam uji ini adalah :

$$
\begin{aligned}
& \begin{array}{c}
X=\frac{\sum X}{N} \\
\sigma_{\chi}=\sqrt{\frac{\sum\left(X_{\mathrm{i}}-\mathrm{X}\right)^{2}}{N-1}}
\end{array} \\
& \text { Rumus uji keseragaman data } \\
& B K A=X+3 \sigma_{\mathrm{x}} \\
& B K B=X-3 \sigma_{\mathrm{x}} \\
& \text { Keterangan : } \\
& X \quad=\text { rata-rata } \\
& \sigma_{\mathrm{x}} \quad=\text { standart deviasi } \\
& \mathrm{N} \quad=\text { jumlah data } \\
& \text { BKA = batas kendali atas } \\
& \mathrm{BKB}=\text { batas kendali bawah }
\end{aligned}
$$

Jika data berada diluar batas kendali atas ataupun batas kendali bawah maka data tersebut dihilangkan, keseragaman data dapat diketahui dengan menggunakan peta kendali $\mathrm{X}^{-}$.

\section{Analisis Pengukuran Mekanika Tubuh Manusia}

\section{Dengan Metode Biomekanika}

Biomekanika merupakan salah satu dari empat bidang penelitian informasi hasil ergonomi. Yaitu penelitian tentang kekuatan fisik manusia yang mencakup kekuatan atau daya fisik manusia ketika bekerja dan mempelajari bagaimana cara kerja serta peralatan harus dirancang agar sesuai dengan kemampuan fisik manusia ketika melakukan aktivitas kerja tersebut.
Dalam biomekanika ini banyak disiplin ilmu yang mendasari dan berkaitan untuk dapat menopang perkembangan biomekanik. Disiplin ilmu ini tidak terlepas dari kompleksnya masalah yang ditangani oleh biomekanik ini.

\section{Recommended Weight Limit (RWL)}

Persamaan untuk menentukan beban yang direkomendasikan untuk diangkat seorang peekerja dalam kondisi tertentu menurut NIOSH adalah $\mathrm{RWL}=\mathrm{LC} \times \mathrm{HM} \times \mathrm{VM} \times \mathrm{DM} \times \mathrm{AM} \times \mathrm{FM} \times \mathrm{CM}$

Setelah nilai RWL diketahui, selanjutnya perhitungan lifting index, untuk mengetahui index pengangkatan yang tidak mengandung resiko cidera tulang belakang, dengan persamaan :

$$
\mathrm{LI}=\frac{\text { Load Weight }}{\text { Recommended Weight Limit }}=\frac{\mathrm{L}}{\mathrm{RWL}}
$$

Keteraangan :

Jika LI $\leq 1$, maka aktivitas tersebut tidak mengandung resiko cidera tulang belakang. Jika LI $>1$, maka aktiivitas tersebut mengandung resiko cidera tulang belakang.

\section{Perhitungan Rangka}

Profil adalah batang yang digunakan pada konstruksi, ada beberapa jenis profil yang digunakan pada pembuatan produk atau perkakas (tools) profil L, profil I, profil U, dan lain-lain. Perhitungan kekuatan rangka yang digunakan yaitu profil O. Perhitungan rangka untuk profil jenis besi pipa 
dijelaskan sebagai berikut :

Menghitung titik berat penampang $(\mathrm{Y})$

$$
\mathrm{Y}=\mathrm{d} / 2
$$

Keterangan :

$$
\begin{aligned}
& \mathrm{Y}=\text { titik berat penampang }(\mathrm{mm}) \\
& \mathrm{d}=\operatorname{diameter} \text { luar }(\mathrm{mm})
\end{aligned}
$$

Menghitung momen inersia

Keterangan :

$$
I_{x \gamma}=\frac{\pi}{64}\left(d^{4}-d_{1}^{4}\right)
$$

$\mathrm{d}_{1}=$ diameter dalam $(\mathrm{mm})$

Menghitung tegangan geser yang diijinkan pada rangka

$$
\begin{aligned}
& \qquad \tau=\frac{M_{\chi} Y}{I_{\chi} Y} \\
& \begin{array}{l}
\text { Keterangan : } \\
\tau=\text { tegangan } \\
(\mathrm{kgf} / \mathrm{mm})
\end{array} \\
& M=\text { momen yang terjadi }(\mathrm{kgf} / \mathrm{mm}) \\
& I_{\chi}=\text { momen inersia batang }(\mathrm{mm}) \\
& Y=\text { titik berat penempang }(\mathrm{mm})
\end{aligned}
$$

Menghitung tegangan ijin profil

$$
\text { Tegangan ijin profil }=\frac{0.5 \cdot \tau(\text { tarik })}{F S}
$$

\section{Keterangan: \\ $\tau($ tarik $)=$ tegangan tarik yang diijinkan \\ $\left(\mathrm{kg} / \mathrm{mm}^{2}\right)$ \\ $\mathrm{FS}=$ factor safety/faktor keamanan (nilai $=2$ )}

\section{METODE PENELITIAN}

\section{Pengumpulan Data}

Tahap pengumpulan data memerlukan beberapa macam data mengenai aktivitas operator pada saat proses taper.

\section{Dokumentasi}

Data ini digunakan untuk mengetahui aktifitas yang terjadi pada proses taper, berupa sikap kerja operato dan alat yang digunakan.

\section{Wawancara}

Wawancara merupakan proses pengambilan data melalui pengisian kuisioner nordic body map yang telah dirancang sesuai tujuan yang ingin dicapai. Penyebaran kuisioner diberikan kepada operator yang terlibat dalam proses taper untuk mengetahui keluhan yang dialami operator dalam melakukan proses taper.

3. Identifikasi keluhan, harapan, dan kebutuhan

Pada tahap ini akan dilakukan interpretasi, harapan dan kebutuhan operator, yang nantinya akan digunakan sebagai dasar perancangan alat bantu untuk proses taper. Hasil rancangan terse but diharapkan mampu memenuhi keluhan, harapan dan kebutuhan operator tersebut.

\section{Data anthropometri}

Dalam perancangan ini diperlukan data anthropometri yang digunakan untuk menetapkan ukuran rancangan. Hal ini dimaksudkan agar rancangan yang dihasilkan dapat digunakan dengan baik atau paling tidak mendekati karakteristik penggunanya.

Rancang Bangun Alat Bantu

1. Penyusunan Konsep Perancangan

Menjelaskan langkah-langkah perancangan, 
pembuatan alat bantu proses taper yang terdiri dari komponen seperti profil/batang besi pipa yang digunakan pada konstruksi.

\section{Perhitungan Teknik}

Perhitungan teknik diperlukan untuk mengetahui kelayakan rancangan apabila rancangan tersebut digunakan. Perhitungan teknik meliputi kekuatan rangka untuk mengetahui kekuatan hasil rancangan terhadap beban maksimal yang diterima penentuan beban, dan perhitungan momen pada titik kritis, serta material.

\section{Pengolahan Data Anthropometri}

Data dari penelitian dikumpulkan kemudiaan diolah terlebih dahulu sebelum ke tahap analisa. Pengolahan data ini meliputi perhitungan mean dan standart deviasi data anthropometri, pengukuran perancangan anthropometri, perhitungan kekuatan material dan perancangan alat bantu taper. Pengolahan data tersebut dijelaskan, sebagai berikut :

1. Perhitungan Uji Keseragaman Data Anthropometri

\section{Perhitungan Persentil}

\section{Perhitungan Biomekanika}

\section{Analisa Dan Interpretasi Hasil}

Pada sub bab ini akan diuraikan mengenai analisa dan interpretasi hasil terhadap pengumpulan dan pengolahan data alat bantu proses taper.

Untuk mengetahui alat bantu Taper yang telah dibuat layak atau tidak, maka perlu di ukur terlebih dahulu, sehingga mengetahui keluhan fisik operator telah menurun dengan menggunakan kuisioner Nordic Body Map dan output produksi apakah telah meningkat di bandingkan sebelum menggunakan alat bantu tersebut.

\section{Pengumpulan dan Pengolahan Data}

\section{Pengumpulan Data}

Metode untuk mendapatkan data awal dilakukan wawancara pada operator, menyebarkan kuisioner Nordic Body Map dan data anthropometri operator taper untuk mendesain alat bantu proses taper.

\section{a. Pengambilan Gambar Sikap Kerja Operator}

Dilakukan dengan mengambil foto sikap tubuh pada saat operator melakukan proses taper

b. Wawancara

Wawancara dilakukan untuk mendapatkan informasi langsung dari operator taper mengenai keluhan yang dirasakan atau dialami pada aktivitas prose taper. Berdasarkan hasil wawancara dengan operator diketahui bahwa waktu rata-rata produksi proses taper adalah 7 jam kerja dan output yang dihasilkan rata-rata 400 pcs dalam 23 hari kerja.

\section{c. Nordic Body Map}

Nordic Body Map diberikan kepada 20 operator tetap pada proses taper, penyebaran kuisioner ini bertujuan untuk memperkuat data dari wawancara sebelumnya agar mengetahui keluhan yang dialami 
mereka setelah melakukan aktivitas proses taper.

Tabel 4. presentase nordic body map

\begin{tabular}{|c|c|c|c|c|c|c|c|c|c|c|c|c|c|c|c|c|c|c|c|c|c|c|c|c|}
\hline \multirow{2}{*}{ no } & \multirow{2}{*}{ jenis keluhan } & \multirow{2}{*}{$\begin{array}{c}\text { tingkat } \\
\text { keluhan }\end{array}$} & \multicolumn{20}{|c|}{ responden } & \multirow{2}{*}{ jumlah } & \multirow{2}{*}{ persentase } \\
\hline & & & 1 & 2 & 3 & 4 & 5 & 6 & 7 & 8 & 9 & 10 & 11 & 12 & 13 & 14 & 15 & 16 & 17 & 18 & 19 & 20 & & \\
\hline \multirow[t]{4}{*}{1} & bahu kiri & a & & & & & & & & & & & & & & & & & & & & & & \\
\hline & & b & $\sqrt{ }$ & $\sqrt{1}$ & $\sqrt{ }$ & $\sqrt{ }$ & $\sqrt{ }$ & $\sqrt{ }$ & & & $\sqrt{ }$ & $\sqrt{1}$ & $\sqrt{ }$ & $\sqrt{ }$ & $\sqrt{ }$ & $\sqrt{ }$ & $\sqrt{ }$ & $\sqrt{ }$ & $\sqrt{ }$ & $\sqrt{ }$ & $\sqrt{ }$ & & 17 & $85 \%$ \\
\hline & & c & & & & & & & $\sqrt{ }$ & $\sqrt{1}$ & & & & & & & & & & & & $\sqrt{ }$ & 3 & $15 \%$ \\
\hline & & d & & & & & & & & & & & & & & & & & & & & & & \\
\hline \multirow[t]{4}{*}{2} & bahu kanan & a & & & & & & & & & & & & & & & & & & & & & & \\
\hline & & $b$ & $\sqrt{ }$ & & & $\sqrt{ }$ & & $\sqrt{ }$ & & & & & & & & & $\sqrt{ }$ & $\sqrt{ }$ & $\sqrt{ }$ & & $\sqrt{ }$ & & 7 & $40 \%$ \\
\hline & & c & & $\sqrt{ }$ & $\sqrt{ }$ & & $\sqrt{ }$ & & $\sqrt{ }$ & $\sqrt{ }$ & $\sqrt{ }$ & $\sqrt{ }$ & $\sqrt{ }$ & $\sqrt{ }$ & $\sqrt{ }$ & $\sqrt{ }$ & & & & $\sqrt{ }$ & & $\sqrt{ }$ & 13 & $60 \%$ \\
\hline & & d & & & & & & & & & & & & & & & & & & & & & & \\
\hline \multirow[t]{4}{*}{3} & pinggang & $a$ & & & & & & & & & & & & & & & & & & & & & & \\
\hline & & b & & & & & & & & & & & & & & & & & & & & & & \\
\hline & & c & $\sqrt{ }$ & & $\sqrt{ }$ & $\sqrt{ }$ & $\sqrt{ }$ & & $\sqrt{ }$ & & $\sqrt{ }$ & & & $\sqrt{ }$ & $\sqrt{ }$ & & $\sqrt{ }$ & & $\sqrt{ }$ & & $\sqrt{ }$ & $\sqrt{ }$ & 12 & $60 \%$ \\
\hline & & d & & $\sqrt{ }$ & & & & $\sqrt{ }$ & & $\sqrt{ }$ & & $\sqrt{ }$ & $\sqrt{ }$ & & & $\sqrt{ }$ & & $\sqrt{ }$ & & $\sqrt{ }$ & & & 8 & $40 \%$ \\
\hline \multirow[t]{4}{*}{4} & lengan bawah kiri & $\bar{a}$ & & & & & & & & & & & & & & & & & & & & & & \\
\hline & & b & $\sqrt{ }$ & $\sqrt{ }$ & $\sqrt{ }$ & $\sqrt{ }$ & & $\sqrt{ }$ & $\sqrt{ }$ & & & & $\sqrt{ }$ & $\sqrt{ }$ & $\sqrt{ }$ & $\sqrt{ }$ & $\sqrt{ }$ & $\sqrt{ }$ & $\sqrt{ }$ & $\sqrt{ }$ & $\sqrt{ }$ & $\sqrt{ }$ & 16 & $80 \%$ \\
\hline & & c & & & & & $\sqrt{ }$ & & & $\sqrt{ }$ & $\sqrt{ }$ & $\sqrt{ }$ & & & & & & & & & & & 4 & $20 \%$ \\
\hline & & d & & & & & & & & & & & & & & & & & & & & & & \\
\hline \multirow[t]{4}{*}{5} & lengan bawah kanan & a & & & & & & & & & & & & & & & & & & & & & & \\
\hline & & $b$ & $\sqrt{ }$ & $\sqrt{ }$ & & & $\sqrt{ }$ & & $\sqrt{ }$ & & $\sqrt{ }$ & & & $\sqrt{ }$ & & & $\sqrt{ }$ & & & & & & 7 & $35 \%$ \\
\hline & & c & & & $\sqrt{ }$ & $\sqrt{ }$ & & $\sqrt{ }$ & & $\sqrt{ }$ & & $\sqrt{ }$ & $\sqrt{ }$ & & $\sqrt{ }$ & $\sqrt{ }$ & & $\sqrt{ }$ & $\sqrt{ }$ & $\sqrt{ }$ & $\sqrt{ }$ & $\sqrt{ }$ & 13 & $65 \%$ \\
\hline & & d & & & & & & & & & & & & & & & & & & & & & & \\
\hline
\end{tabular}

d. Identifikasi Keluhan, Harapan Dan Kebutuhan

Perancangan.

Identifikan dilakukan dengan wawancara, memberikan pertanyaan langsung kepada 20 operator taper untuk mendapatkan informasi secara langsung dari para operator mengenai kesulitan atau keluhan yang dialami pada waktu proses taper.

e. Identifikasi Mesin-Mesin Yang Digunakan Untuk Proses Taper

Identifikasi mesin yang digunakan untuk proses taper dilakukan untuk mengetahui kondisi mesin yang digunakan untuk proses taper yang saat ini digunakan sebagai informasi awal untuk mengetahui kekurangan yang ada dan proses perbaikan yang perlu di lakukan.

\section{f. Identifikasi Biomekanika Awal}

Identifikasi biomekanika awal digunakan untuk menganalisis penyebab dari keluhan paling dominan yaitu sakit pada bagian pinggang operator taper.

\section{Dimensi Anthropometri}

Perancangan dimensi rangka dihitung dengan menggunakan data anthropometri tinggi siku berdiri tegak (TSB) dan jangkauan tangan kedepan (JT), data tersebut digunakan untuk menentukan dimensi panjang dan tinggi rangka alat bantu. Data anthropometri yang digunakan dalam perhitungan ini yaitu data anthropometri operator taper sebanyak 20 orang. 
Tabel 5. Data Tinggi Siku Berdiri (TSB) dan

Jangkauan Tangan Kedepan (JT)

\begin{tabular}{|c|c|}
\hline Data ke- & TSB $(\mathrm{cm})$ \\
\hline 1 & 95 \\
\hline 2 & 100 \\
\hline 3 & 104 \\
\hline 4 & 97 \\
\hline 5 & 96.5 \\
\hline 6 & 99 \\
\hline 7 & 102 \\
\hline 8 & 99 \\
\hline 9 & 98 \\
\hline 10 & 97.4 \\
\hline 11 & 103 \\
\hline 12 & 98.1 \\
\hline 13 & 97 \\
\hline 14 & 95.9 \\
\hline 15 & 103.4 \\
\hline 16 & 99.3 \\
\hline 17 & 95.2 \\
\hline 18 & 104 \\
\hline 19 & 99 \\
\hline 20 & 95.8 \\
\hline
\end{tabular}

\begin{tabular}{|c|c|}
\hline Data ke- & $\mathrm{JT}(\mathrm{cm})$ \\
\hline 1 & 73.5 \\
\hline 2 & 70 \\
\hline 3 & 72 \\
\hline 4 & 71 \\
\hline 5 & 73 \\
\hline 6 & 71.5 \\
\hline 7 & 72 \\
\hline 8 & 73.5 \\
\hline 9 & 73 \\
\hline 10 & 69 \\
\hline 11 & 71.5 \\
\hline 12 & 70.8 \\
\hline 13 & 70 \\
\hline 14 & 73 \\
\hline 15 & 70 \\
\hline 16 & 72 \\
\hline 17 & 73 \\
\hline 18 & 70 \\
\hline 19 & 72.5 \\
\hline 20 & 70 \\
\hline
\end{tabular}

\section{Pengolahan Data}

\section{a. Penyusunan Konsep Perancangan}

Desain konsep diperlukan dalam suatu perancangan. Desain konsep meliputi bentuk dasar, dimensi utama yang fungsional, dan mekanisme kerja. Konsep perancangan ini memberikan gambaran awal mengenai alat yang akan dibuat dan bagaimana mekanisme kerja dengan mempertimbangkan kesesuaian operator yang akan menggunakannya.

\section{b. Konsep Desain}

Konsep desain dari perancangan alat bantu ini adalah gambaran secara garis besar mengenai alat bantu yang akan dibuat, mempermudah perhitungan teknik seperti penentuan dimensi alat, dan peletakan alat yang tepat.

c. Pengujian Data Anthropometri
Data anthropometri yang telah dikumpulkan dihitung masing-masing mean dan standart deviasinya.

d. Penentuan Dimensi Rancangan Rangka Alat Bantu

Perhitungan dimensi dilakukan untuk menentukan ukuran rancangan yang akan dibuat. Perhitungan dimensi ini mengacu pada hasil perhitungan persentil yang telah dilakukan sebelumnya.

Identifikasi Biomekanika

Dalam sub bab ini peneliti ingin mengetahui apakah aktivitas pengangkatan yang dilakukan pada proses taper setelah adanya alat bantu telah memenuhi standart.

\section{ANALISIS DAN INTERPRETASI HASIL}

\section{Analisis Hasil Penelitian}

Analisis hasil penelitian yang dilakukan adalah analisis terhadap rancangan alat bantu, analisis material alat bantu proses taper, tinggi anthropometri operator dan aspek ekonomisnya. Analisis secara lebih jelas dijelaskan, sebagai berikut :

a. Analisis Proses Taper Sebelum Dibuatkan Alat Bantu

Sebelum terdapat alat bantu pada proses taper, hasil dari taper yang di proses kurang sesuai standart dikarenakan permukaan ujung material yang dipanaskan hanya dikira-kira oleh operator dan operator banyak mengalami keluhan fisik pada bagian 
tubuh mereka.

b. Analisis Proses Taper Setelah Dibuatkan Alat

\section{Bantu}

Pembuatan alat bantu visualisasi pada mesin heating memudahkan operator dalam menempatkan material yang akan dipanaskan ujungnya, hal ini dapat membatu operator dalam memanaskan ujung material sehingga proses taper dapat berjalan dengan cepat.

Dalam perancangan alat bantu taper peneliti tidak merubah sikap atau posisi kerja operator, peneliti hanya memberikan alat bantu berupa pipa besi untuk membantu jalanya proses taper, hal ini dilakukan bedasarkan keluhan dan pertimbangan hasil wawancara serta penyebaran kuesioner yang diberikan kepada operator. Perancangan dilakukan dengan menggunakan pendekatan anthropometri, sehingga diharapkan dapat meminimalisir keluhankeluhan yang dirasakan.

\section{Analisis Biomekanika}

Dalam sub bab ini peneliti ingin mengetahui apakah aktivitas pengangkatan yang dilakukan pada proses taper setelah adanya alat bantu telah memenuhi standart.

\section{Sebelum Dibuatkan Alat Bantu}

LI $\geq 1$, maka aktivitas tersebut mengandung resiko cidera tulang belakang bagi operator taper.

Setelah Dibuatkan Alat Bantu

$\mathrm{LI} \leq 1$, maka aktivitas tersebut tidak mengandung resiko cidera tulang belakang bagi operator taper

\section{Interpretasi Hasil}

Perbandingan Produktivitas Proses Taper Sebelum Dan Sesudah Dibuatkan Alat Bantu

Tabel 6. Perbandingan Produktivitas Proses Taper Sebelum Dan Sesudah Dibuatkan Alat Bantu

\begin{tabular}{|c|c|c|c|c|c|c|c|c|}
\hline \multicolumn{1}{|c|}{ Sebelum Dibuatkan Alat Bantu } & \multicolumn{5}{|c|}{ Sesudah Dibuatkan Alat Bantu } \\
\hline \multirow{2}{*}{ Data Proses Taper } & 2013 & \multicolumn{2}{|c|}{2014} & \multicolumn{5}{|c|}{2014} \\
\cline { 2 - 10 } & Des'13 & Jan'14 & Feb'14 & Mar'14 & Apr'14 & Mei'14 & Jun'14 & Jul'14 \\
\hline Rata-Rata Output Taper & 350 & 420 & 454 & 640 & 674 & 680 & 684 & 714 \\
\hline Po/Bln & 6960 & 13400 & 7740 & 9640 & 7920 & 11740 & 9810 & 12340 \\
\hline Rata-Rata PO /Bln & 7000 & \multicolumn{2}{|c|}{10570} & \multicolumn{5}{|c|}{10290} \\
\hline Hari Dibutuhkan & 20 & 25 & 23 & 16 & 15 & 15 & 15 & 14 \\
\hline Output (Rata - Rata) & 408 & 408 & 408 & 640 & 674 & 680 & 684 & 714 \\
\hline Hari Kerja (7 Jam) & \multicolumn{9}{|c|}{23} & \multicolumn{5}{c|}{15} \\
\hline
\end{tabular}

Dari tabel diatas dapat dilihat hasil output rata hanya 15 hari kerja

- rata sebelum dibuatkan alat bantu sebanyak 408 pes dalam kurun waktu 23 hari kerja, dan hasil output rata - rata setelah dibuatkan alat bantu sebanyak 678 pes dalam kurun waktu

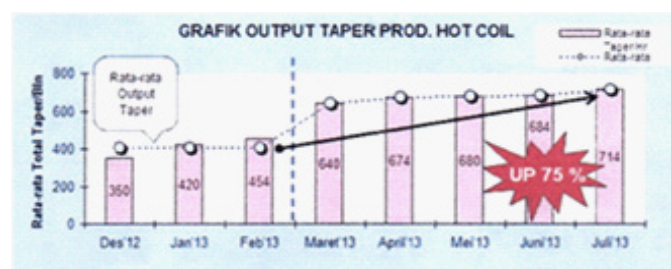


Hasil grafik menunjukkan output taper pada produksi hot coil telah meningkat $75 \%$ setelah dibuatkan alat bantu.

Dari hasil kuesioner yang disebar pada setiap opertaor setelah dibuatkan alat bantu, operator taper tidak lagi mengalami keluhan fisik yang selama ini dirasakan ketika proses taper berjalan.

\section{KESIMPULAN DAN SARAN}

\section{Kesimpulan}

Kesimpulan yang dapat diambil dari penelitian ini adalah sebagai berikut :

1. Faktor - faktor yang mempengaruhi keluhan fisik operator taper disebabkan dari beban material yang di angkat oleh operator dan sikap tubuh operator yang membungkuk pada aktivitas yang terdapat pada proses taper, sehingga kendala yang dihadapi oleh operator taper adalah rasa sakit pada bagian tubuh operator seperti pada bahu kiri, bahu kanan, pinggang, lengan bawah kiri dan lengan bawah kanan, hal tersebut juga berpengaruh pada produktivitas dari proses taper sehingga output taper kurang maksimal.

2. Mengurangi keluhan fisik operator dengan membuatkan alat bantu yang ergonomis pada proses taper dengan rancangan yang sesuai menurut postur tubuh, data anthropometri dan data persentil dari setiap operator taper sehingga dapat ditentukan 36 tinggi alat bantu, jarak antara mesin dengan alat bantu dan panjang dari alat bantu tersebut.

Dalam analisis perhitungan biomekanika aktivitas yang aman dari cidera tulang belakang adalah $\mathrm{LI} \leq$ 1, sebelum adanya alat bantu pada proses taper LI $=2,492$ maka aktivitas tersebut mengandung resiko cidera tulang belakang dan setelah dibuatkan alat bantu maka analisis biomekanika yang sebelumnya $\mathrm{LI}=2,492$ menjadi $\mathrm{LI}=0,77$ sehingga resiko cidera tulang belakan dapat dihilangkan.

3. Rancangan alat bantu yang ergonomis dapat mengurangi keluhan fisik yang terjadi akibat aktivitas dari proses taper tersebut, hal tersebut juga dapat membuat produktivitas dari operator proses taper bertambah sehingga output produksipun dapat meningkat.

4. Dengan bantuan alat bantu untuk proses taper maka produktivitas dari proses taper dapat meningkat dan output produksipun dapat meningkat pula

\section{Saran}

Saran yang dapat diberikan untuk langkah pengembangan atau penelitian selanjutnya, adalah sebagai berikut :

1. Desain rancangan alat bantu untuk proses taper sebaiknya bahan yang tahan panas, dikarenakan material yang akan di taper merupakan material panas setelah proses heating. 
2. Pengembangan rancangan alat bantu untuk proses taper dengan extend adjustable style, dimana tinggi dari penyangga alat bantu dapat diatur dan disesuaikan dengan tinggi operator yang bervariasi.

\section{DAFTAR PUSTAKA}

Barnes, R.M. Motion and Time Study, Design and Measurement of Work. New York, USA : John Wiley \& Sons, Inc,. 1982.

Nurmianto, Eko. Ergonomi Konsep Dasar dan aplikasinya. Surabaya: penerbit guna widya, 2004.

Tarwaka, Bakri, SHA. Ergonomic Untuk Kesehatan dan Keselamatan Kerja Dan Produktivitas. Surakarta : penerbit UNIBA press, 2004.

Wignjosoebroto, sritomo. Ergonomi Studi Gerak dan Waktu. Surabaya : penerbit guna widya, 1995.

Wignjosoebroto, sritomo. Teknik Tata Cara dan Pengukuran Kerja. Jakarta : penerbit guna widya, 1992. 